\title{
Clinical results of conformal versus intensity-modulated radiotherapy using a focal simultaneous boost for muscle- invasive bladder cancer in elderly or medically unfit patients
}

\author{
Lotte J. Lutkenhaus ${ }^{*}$ (D), Rob M. van Os, Arjan Bel and Maarten C. C. M. Hulshof
}

\begin{abstract}
Background: For elderly or medically unfit patients with muscle-invasive bladder cancer, cystectomy or chemotherapy are contraindicated. This leaves radical radiotherapy as the only treatment option. It was the aim of this study to retrospectively analyze the treatment outcome and associated toxicity of conformal versus intensitymodulated radiotherapy (IMRT) using a focal simultaneous tumor boost for muscle-invasive bladder cancer in patients not suitable for cystectomy.

Methods: One hundred eighteen patients with T2-4 N0-1 MO bladder cancer were analyzed retrospectively. Median age was 80 years. Treatment consisted of either a conformal box technique or IMRT and included a simultaneous boost to the tumor. To enable an accurate boost delivery, fiducial markers were placed around the tumor. Patients were treated with $40 \mathrm{~Gy}$ in 20 fractions to the elective treatment volumes, and a daily tumor boost up to 55-60 Gy.

Results: Clinical complete response was seen in $87 \%$ of patients. Three-year overall survival was $44 \%$, with a locoregional control rate of $73 \%$ at 3 years. Toxicity was low, with late urinary and intestinal toxicity rates grade $\geq 2$ of 14 and $5 \%$, respectively. The use of IMRT reduced late intestinal toxicity, whereas fiducial markers reduced acute urinary toxicity.

Conclusions: Radical radiotherapy using a focal boost is feasible and effective for elderly or unfit patients, with a 3 -year locoregional control of $73 \%$. Toxicity rates were low, and were reduced by the use of IMRT and fiducial markers.
\end{abstract}

Keywords: Radical radiotherapy, Focal boost, Bladder cancer, Intensity-modulated radiotherapy, Toxicity

\section{Background}

Standard therapy for muscle-invasive bladder cancer is radical cystectomy with bilateral lymph node dissection [1], providing 3-year recurrence-free survival rates of 60-68 \% [2-5]. Bladder-preserving strategies, such as trimodality treatments combining radiochemotherapy with a transurethral resection of the bladder tumor (TUR-B) are usually only offered to patients who refuse cystectomy or who are considered inoperable [6-8]. The

\footnotetext{
* Correspondence: I.j.lutkenhaus@amc.uva.nl

Department of Radiation Oncology, Academic Medical Center, Meibergdreef 9, 1105 AZ Amsterdam, The Netherlands
}

superiority of surgery over a bladder-preserving strategy has not been proven in a randomized trial, although long-term data shows that overall survival for both strategies is comparable $[1,9-11]$. It has been shown that a combination of radiotherapy and chemotherapy results in a higher locoregional control and overall survival compared to radiotherapy alone $[6,12,13]$, resulting in radiochemotherapy being the preferred bladder-sparing treatment option. However, patients who are referred for bladder-sparing approaches are mostly elderly or unfit, which regularly also contraindicates chemotherapy [14]. 
This leaves the combination of TUR-B and radical radiotherapy as the only treatment option.

Radiotherapy techniques have improved over the past years, from box techniques incorporating the entire pelvis, to adaptive strategies combined with rotational delivery reducing normal tissue doses [15-21]. For radical radiotherapy delivered with large, non-modulated treatment fields for both the bladder and the tumor boost area, without using daily image-guidance, relatively low three-year local control rates of 53-56 \% have been reported [22-24]. For these radiotherapy treatments, with tumor doses between 55 and $70 \mathrm{~Gy}$, acute and late toxicity rates grade $\geq 2$ ranged between $20-67 \%$, and 7-17 \%, respectively [22, 25-29]. More conformal treatment plans have shown to result in reduced toxicity [26], and seem promising in terms of local control when combined with daily image-guidance [30-32]. However, these studies consist of small patient numbers, and frequently have a short follow-up.

The aim of the present retrospective study was to analyze the treatment outcome and associated toxicity of conformal versus intensity-modulated radiotherapy, without concurrent chemotherapy, using a focal simultaneous boost for muscle-invasive bladder cancer in patients considered medically or technically inoperable.

\section{Methods}

From 2003 to 2013, 132 patients with a muscle-invasive urothelial cell carcinoma of the bladder were treated with radical radiotherapy at the Academic Medical Center, The Netherlands. Of these, 8 patients were also included in a previous analysis [23]. Inclusion of patients was started upon implementation of an adaptive strategy [17], which yielded the range of used treatment techniques as homogeneous as we could achieve. Patients with multiple tumors were excluded, resulting in 118 patients available for analysis. The results were evaluated retrospectively. Patient and treatment characteristics are shown in Table 1. Median age at start of radiotherapy was 80 years (range: 41-95 years). All patients had a histologically diagnosed solitary T2-4 N0-1 M0 bladder tumor, and were inoperable, refused surgery or were medically unfit for radical surgery due to age or comorbidities. Staging procedures included clinical and digital rectal examination, chest Xray, a pelvic and abdominal CT scan and cystoscopy. All patients underwent TUR-B prior to radiotherapy. Tumors were scored as T3 when a mass was palpated after the TUR-B, or when the CT scan revealed tumor extension in the perivesical fatty tissue. When muscle infiltration depth was unknown, the tumor was scored as T2.

\section{Radiotherapy}

Patients were treated in 20 daily fractions, over a period of 4 weeks. The prescription dose to the elective area, i.e. bladder, prostate and pelvic lymph nodes, was $40 \mathrm{~Gy}$.
Table 1 Patient and treatment characteristics

\begin{tabular}{lll}
\hline Characteristics & Patients & \\
\cline { 2 - 3 } & $n$ & $(\%)$ \\
\hline Sex & 29 & $(25)$ \\
Female & 89 & $(75)$ \\
Male & & \\
WHO performance status & 13 & $(11)$ \\
0 & 67 & $(57)$ \\
1 & 35 & $(30)$ \\
2 & 3 & $(2)$ \\
3 & & \\
Tumor stage & & \\
2 & 37 & $(31)$ \\
3 & 71 & $(60)$ \\
4 & 10 & $(9)$ \\
Histological grade & & \\
2 & 11 & \\
3 & 107 &
\end{tabular}

Clinical lymph node involvement ${ }^{\mathrm{b}}$

No 109

(92)

Yes

Hydronephrosis

No

(82)

Yes

Tumor size

$2-4 \mathrm{~cm} \quad 37$

(31)

$4-6 \mathrm{~cm}$

(49)

$\geq 6 \mathrm{~cm}$

(19)

Unknown

(1)

Tumor resection status

Not resected 2

(2)

Complete resection

Incomplete resection

Unknown

Planned radiotherapy dose

55 Gy

$60 \mathrm{~Gy}$

Radiotherapy technique

3D-conformal

(57)

IMRT

(36)

VMAT

Focal simultaneous boost

Concomitant

Simultaneously integrated

2)

$(11)$
$(30)$
$(2)$
$(31)$
$(60)$
$(9)$
$(91)$

(82)

1)

9)

(1)

(5)


Table 1 Patient and treatment characteristics (Continued)

Treated with image-guidance

No

Yes

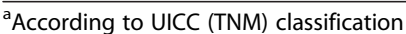

${ }^{b}$ Patients with positive lymph nodes were not referred for radical radiotherapy. However, patients with one clinically dubious but not pathologically proven local node were included

Lymph nodes were excluded from the elective field in case of comorbidities that required a target volume reduction. The tumor received a simultaneous boost of 0.75 Gy, delivered either concomitantly or simultaneously integrated with the elective dose. Before 2006, a total prescription dose of 55 Gy to the tumor was used. After 2006, a dose of 60 Gy was chosen, unless this would result in a too high small bowel dose (bowel volume receiving $60 \mathrm{~Gy}>3 \mathrm{~cm}^{3}$ ). It was chosen to increase the tumor dose, since a previously conducted study at our institute showed a low toxicity profile for the 55 Gy schedule [23], leaving room for dose escalation and taking into account that no concurrent chemotherapy was administered. The additional 5 Gy dose was delivered in two fractions of 2.5 Gy at the end of treatment.

A CT scan with contrast filling for the bowel was acquired prior to treatment and used for planning purposes. Patients were instructed to have a full bladder during CT scanning and during treatment, by drinking $250 \mathrm{ml}$ of fluid $1.5 \mathrm{~h}$ prior to treatment, and refrain from voiding in order to minimize the volume of noninvolved bladder tissue receiving the boost dose. The bladder and gross tumor volume (GTV) were delineated on the planning CT scan. From 2004 onwards, GTV delineation was often aided by the cystoscopic placement of fiducial markers (used in $64 \%$ of patients). At first, titanium clips were used [33], which were replaced by lipiodol in 2006 [34]. At the introduction of intensity-modulated radiotherapy (IMRT), the pelvic lymph nodes, prostate, rectum, small bowel cavity and femoral heads were also delineated on the planning CT scan. Three different planning techniques have been used between 2003 and 2013, which are described below. Table 1 lists the number of patients treated with each radiotherapy planning technique. Table 2 provides an overview of the used techniques.

Before 2009, a conformal four-field box was used for the elective field, and the concomitant boost was delivered using 2-4 conformal beams. The cranial limit of the elective field was the L5-S1 interspace and the caudal limit was $5 \mathrm{~mm}$ caudal of the symphysis. Lateral margins were $10 \mathrm{~mm}$ beyond the maximal width of the bony pelvis, whereas the anteroposterior margins on the lateral fields were $15 \mathrm{~mm}$ beyond the bladder. The planning target volume (PTV) for the tumor, i.e. PTV $\mathrm{P}_{\text {boost }}$, was obtained by expanding the GTV with a $15-20 \mathrm{~mm}$ margin in case no fiducial markers were present, as opposed to $10 \mathrm{~mm}$ in case of markers. When markers were not present, an adaptive margin strategy for $\mathrm{PTV}_{\text {boost }}$ was used, for which the GTV was redelineated on daily repeat CT scans acquired during the first week [17]. A summation of all GTV delineations was then expanded with $10 \mathrm{~mm}$ to create a second $\mathrm{PTV}_{\text {boost }}$, which was used from the second week onwards. Weekly offline position verification was performed using electronic portal images, which was replaced by cone beam CT (CBCT) in 2007.

From 2009 onwards, patients were treated with an IMRT technique. For this, a PTV elective was created by expanding the combined bladder, prostate and lymph node delineations with $15 \mathrm{~mm}$ in cranial and anterior directions, and $8 \mathrm{~mm}$ in all other directions. PTV $_{\text {boost }}$ was created as described before. Before October 2011, patients were treated with two separate IMRT-plans with 5 or 7 beams, for both the PTV elective and the concomitant PTV boost [15]. After October 2011, the boost dose was delivered simultaneously integrated with the elective dose. Standard planning objectives were used to obtain a target coverage of $95 \%$ of the prescribed dose to $99 \%$ of the PTV, while keeping dose to the organs at risk as low as possible. The introduction of IMRT was accompanied by the introduction of daily image-guidance using CBCT scans.

Table 2 Treatment planning and delivery methods

\begin{tabular}{|c|c|c|c|c|c|}
\hline & \multicolumn{3}{|c|}{ Elective } & \multicolumn{2}{|l|}{ Boost $^{a}$} \\
\hline & Dose & Target organs & PTV & Dose $^{b}$ & Delivery \\
\hline 3D-conformal & $40 \mathrm{~Gy}$ & Bladder, prostate, and pelvic lymph nodes ${ }^{c}$ & $\begin{array}{l}\text { Box technique, based on } \\
\text { anatomical landmarks }\end{array}$ & $55-60$ Gy & Concomitant \\
\hline \multirow[t]{2}{*}{ IMRT } & 40 Gy & Bladder, prostate, and pelvic lymph nodes ${ }^{c}$ & Cranially and anteriorly: $15 \mathrm{~mm}$. & 55-60 Gy & Concomitant \\
\hline & & & Other directions: 8 mm & $55-60$ Gy & Simultaneously integrated $^{d}$ \\
\hline \multirow[t]{2}{*}{ VMAT } & 40 Gy & Bladder, and pelvic lymph nodes ${ }^{c}$ & Cranially and anteriorly: 13 mm. & $55-60 \mathrm{~Gy}$ & Simultaneously integrated \\
\hline & & & Other directions: 7 mm & & \\
\hline
\end{tabular}

${ }^{a}$ In case fiducial markers were present, a uniform boost margin of $10 \mathrm{~mm}$ was used. Otherwise, an adaptive margin strategy was employed

${ }^{\mathrm{b}} \mathrm{A}$ dose of $60 \mathrm{~Gy}$ was standard after 2006. 55 Gy was chosen only when a dose of 60 Gy would result in a too high small bowel dose

'Lymph nodes were excluded from the elective field in case of comorbidities that required a target volume reduction

${ }^{d}$ Simultaneous integration of the boost plan with the elective plan was implemented after October 2011 
In 2012, rotational delivery of IMRT, i.e. volumetric modulated arc therapy (VMAT), was implemented at our department. Margins to create $\mathrm{PTV}_{\text {elective }}$ were reduced to $13 \mathrm{~mm}$ cranially and anteriorly, and $7 \mathrm{~mm}$ in all other directions, and the prostate was removed from the elective target volume for tumors not located in the bladder neck or prostatic urethra. The previously described adaptive margin strategy was used for $\mathrm{PTV}_{\text {boost }}$ in case no markers were present, otherwise a uniform margin of $9 \mathrm{~mm}$ was used. A daily simultaneously integrated dose of $0.75-1$ Gy was delivered to PTV boost. Dual arc VMAT plans were created, and the same planning objectives were used as for IMRT.

\section{Follow-up}

All patients that started treatment were included in the analysis of overall survival. Six patients who did not complete treatment were excluded from locoregional control analysis. Patients were seen by their radiation oncologist every week during the treatment course, 1 month after treatment, every 3 months thereafter for the first year, every 6 months thereafter up to 3 years, and once yearly up to 5 years. A cystoscopy was performed at 2 months after treatment and thereafter every 6 months. In case of locoregional symptoms or when endoscopically a non-complete response was observed, an additional cystoscopy or CT scan was performed. Complete response was defined as endoscopically no signs of vital tumor, whereas a partial response was defined as a tumor mass reduction $>50 \%$. All invasive and non-invasive recurrences in the bladder were scored as local progression. Urinary and intestinal toxicity were scored according to the Common Terminology Criteria for Adverse Events (CTCAE) version 4.0. Acute toxicity was scored as the maximum toxicity during treatment or the first 3 months thereafter, whereas late toxicity was the maximum toxicity occurring after 3 months. Bladder capacity was estimated by the patient, both before treatment and during follow-up. To this end, patients were asked to measure their maximum voiding volume at home, by voiding in a urinal or cup with volumetric indications. In addition, patients were asked during followup if their voiding capacity was improved or worsened compared to the initial capacity before treatment.

\section{Statistical analysis}

All time intervals were calculated from the start of radiotherapy treatment. Locoregional control was defined as no histological proven nodal or bladder recurrence, whereas distant control was defined as no evidence of distant metastasis. Bladder-intact survival was defined as the survival without a muscle-invasive recurrence (either no recurrence or a successfully treated superficial recurrence) and without a salvage cystectomy.
The Kaplan-Meier method was used to estimate survival. Possible predictors for survival and locoregional recurrence were examined in univariate cox proportional hazard regression analyses. Hazard ratios (HR) were calculated, with associated $95 \%$ confidence intervals $(\mathrm{CI})$ and $\mathrm{p}$-values. For predictors with continuous values both a linear and non-linear (i.e. cubic spline) association with the specific outcome were tested. The toxicity scores were dichotomized into grade $\geq 1$, grade $\geq 2$ and grade $\geq 3$. Possible predictors for toxicity were analyzed using logistic regression in case of predictors with continuous values, or the $\chi^{2}$ test for dichotomous predictors. The difference in pre- and posttreatment functional bladder capacity was tested using a paired $t$-test. A $\mathrm{p}$-value $<0.05$ was considered statistically significant, and statistical analysis was performed using $\mathrm{R}$ (version 3.1.0, The R Foundation for Statistical Computing, Vienna, Austria).

\section{Results}

The median time of follow up was 23.7 months. First response measurements $(n=106)$ showed a complete response in 92 patients $(87 \%)$, and a partial response in 11 patients $(10 \%)$. One patient had stable disease, and 2 patients showed progression. Out of all 118 patients, 20 patients $(17 \%)$ developed a recurrence in the bladder during follow-up, of which 3 patients had a nodal recurrence. Four patients (3\%) developed a nodal recurrence without bladder recurrence, and 27 patients (23\%) developed a distal recurrence. Of the local recurring patients, 9 patients (45\%) experienced both a locoregional and distal recurrence. Six bladder recurrences were superficial and were treated with TUR-B and mitomycin $C$ installations, whereas in the remaining 14 patients, local recurrences were muscle-invasive.

The overall survival after 3 years was $44 \%$ (95\% CI 36-55 \%; Fig. 1). 37 patients died with bladder carcinoma, whereas 24 patients died from intercurrent disease. Two patients died from treatment complications. Bladder-intact survival after 3 years was $84 \%$ (95 \% CI 75-92\%). The 3-year locoregional and distant control rates were $73 \%$ (95 \% CI 64-84 \%; Fig. 2) and $74 \%$ (95\% CI 65-84\%), respectively.

On univariate analysis, a significant difference in overall survival or locoregional disease recurrence was not found for patients treated with either 3D-conformal radiotherapy or IMRT/VMAT. The only significant predictors for survival were age and not completing treatment (Tables 3 and 4). For locoregional disease recurrence, only the presence of hydronephrosis was a statistically significant predictive factor (Table 3). Locoregional control after 3 years was similar for patients receiving either 55 or $60 \mathrm{~Gy}$, with 72 and $74 \%$, respectively $(p=0.55)$. The prognostic value for none of the predictors improved by assuming a nonlinear relationship. 


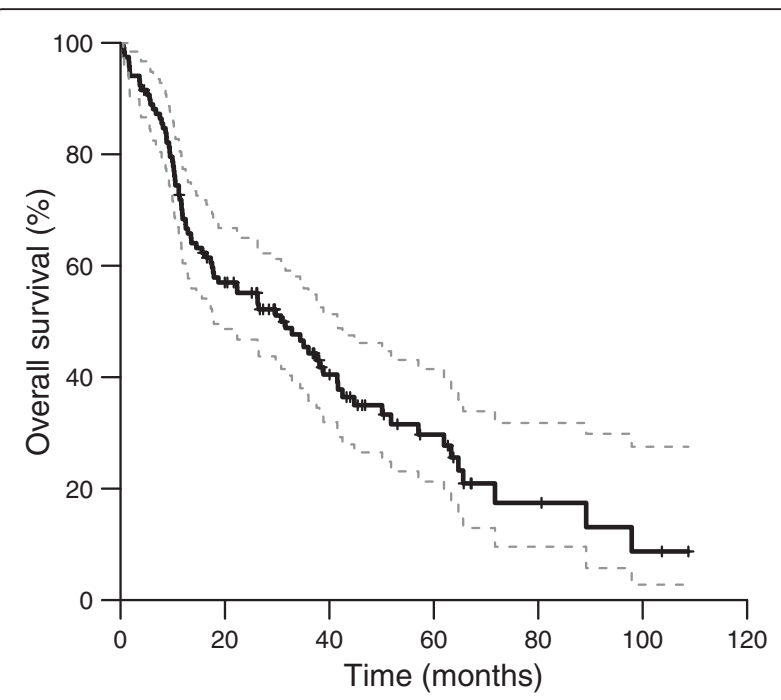

Fig. 1 Overall survival (95\% confidence intervals depicted in grey dashed lines)

Acute intestinal and urinary toxicity was scored in 72 patients. Of these, $19 \%$ experienced grade 2 or higher intestinal toxicity, compared to $26 \%$ for urinary toxicity (see Fig. 3a). Late toxicity was scored in 100 patients. Late intestinal and urinary toxicity grade $\geq 2$ was seen in 5 and $14 \%$ of these patients, respectively (see Fig. 3b). Grade 3 intestinal toxicity was seen in 1 patient, and grade 4 in 2 patients. In 1 patient, grade 4 urinary toxicity was observed.

Univariate analysis revealed that the use of IMRT, combined with daily image-guidance, reduced late intestinal toxicity from $20 \%$ for the conformal box technique, to $5 \%$ for the intensity-modulated techniques $(p=0.05)$. In addition, the introduction of IMRT also influenced acute

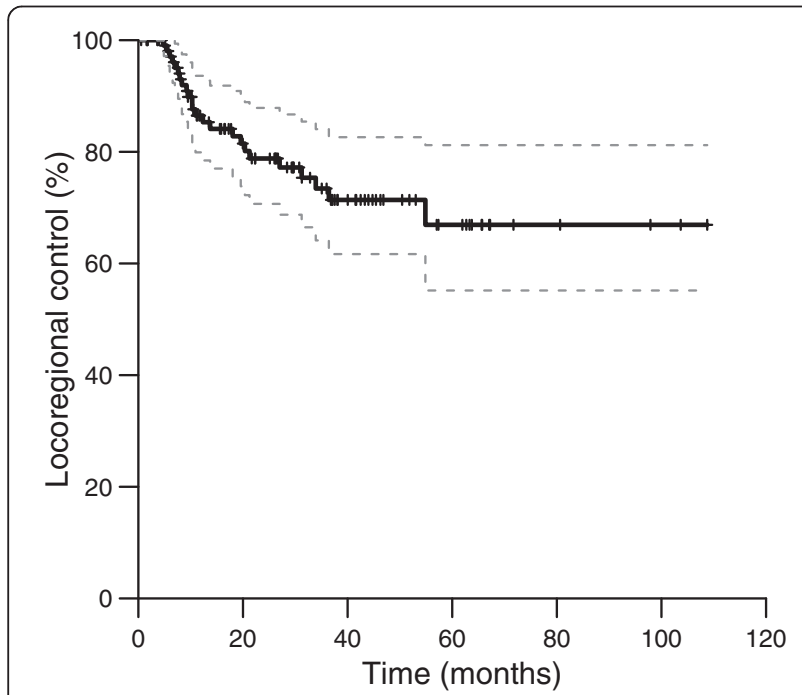

Fig. 2 Locoregional control (95\% confidence intervals depicted in grey dashed lines) urinary toxicity (grade $\geq 3$ toxicity reduced from 22 to $2 \%$, $p=0.02)$. Acute urinary toxicity was furthermore influenced by the use of fiducial markers, with a reduction in grade $\geq 2$ toxicity from $53 \%$ without markers, to $17 \%$ with markers $(p<0.01)$. Logistic regression revealed a relationship between tumor size and acute intestinal and urinary toxicity, with tumor sizes of 2,4 , and $6 \mathrm{~cm}$ corresponding to risks of grade $\geq 1$ acute intestinal toxicity of 45,79 , and $94 \%$, respectively $(p<0.01)$, and risks of grade $\geq 3$ urinary toxicity of 1,4 and $18 \%$, respectively $(p=0.04)$. Other characteristics were not predictive for either late intestinal or urinary toxicity (see Additional file 1: Table S1-S3).

Of the 96 patients for which information about bladder function is available, $92 \%$ reported a stable or improved bladder function. Functional bladder capacity increased significantly, from a median of $200 \mathrm{ml}$ before, to $250 \mathrm{ml}$ after treatment $(p=0.004)$.

\section{Discussion}

In the present study, we found a 3-year overall survival of $44 \%$ for patients treated with TUR-B and radiotherapy with a focal simultaneous boost for bladder cancer, with a 3-year locoregional control of $73 \%$. Of the patients that were still alive after 3 years, $83 \%$ had an intact bladder. We found acute urinary and intestinal toxicity rates grade $\geq 2$ of 26 and $19 \%$, respectively, whereas late urinary and intestinal toxicity grade $\geq 2$ was $14 \%$ and $5 \%$, respectively. Toxicity rates were lower for patients treated with IMRT or fiducial markers around the tumor.

Our results are similar compared to a multicenter phase III trial by James et al., in which 360 patients were randomly assigned to undergo radiotherapy either with or without synchronous chemotherapy [6]. When comparing the radiotherapy-only results from their study with the current study, similar 3-year overall survival rates were found (Fig. 1) [6]. However, the results from chemoradiation as reported by James et al. compare favorably to our results, with a 3-year overall survival for chemoradiation of $57 \%$, compared to $44 \%$ for the present study (Fig. 1). Our low survival rate probably reflects the selection of elderly or medically frail patients, who are likely to have a shorter survival independent of their bladder cancer or treatment. The 3-year locoregional control of $73 \%$ found in the current study, compares favorably with other studies reporting on patients treated with radiotherapy only, which present rates of 53-64\% $[22,25,27,28]$. The exclusion of patients that did not complete radiotherapy, and patients with multifocal tumors, will partly account for this effect. The higher accuracy of dose delivery, by means of fiducial markers and position verification with daily $\mathrm{CBCT}$, may also contribute to the high locoregional control rate. Locoregional control was not influenced significantly by the tumor 
Table 3 Prognostic value for overall survival and locoregional recurrence of patient and tumor characteristics

\begin{tabular}{|c|c|c|c|c|c|c|c|c|}
\hline \multirow[t]{2}{*}{ Prognostic factors } & \multicolumn{4}{|c|}{ Overall survival } & \multicolumn{4}{|c|}{ Locoregional recurrence } \\
\hline & $n$ & $\mathrm{HR}$ & $95 \% \mathrm{Cl}$ & $p$ & $n$ & $\mathrm{HR}$ & $95 \% \mathrm{Cl}$ & $p$ \\
\hline Age & 118 & 1.0 & $(1.0 ; 1.1)$ & 0.02 & 112 & 1.0 & $(0.95 ; 1.0)$ & 0.89 \\
\hline Tumor size & 117 & 1.0 & $(0.90 ; 1.2)$ & 0.62 & 111 & 1.0 & $(0.76 ; 1.3)$ & 0.99 \\
\hline \multicolumn{9}{|c|}{ Residual mass after resection ${ }^{a}$} \\
\hline Yes & 57 & & & & 52 & & & \\
\hline Possibly & 27 & 0.81 & $(0.45 ; 1.5)$ & 0.49 & 27 & 0.83 & $(0.29 ; 2.4)$ & 0.73 \\
\hline No & 16 & 0.47 & $(0.20 ; 1.1)$ & 0.09 & 15 & 0.80 & $(0.22 ; 2.9)$ & 0.73 \\
\hline \multicolumn{9}{|l|}{ Tumor location } \\
\hline Not mobile part & 27 & & & & 25 & & & \\
\hline Mobile part & 91 & 1.05 & $(0.61 ; 1.8)$ & 0.85 & 87 & 0.85 & $(0.34 ; 2.1)$ & 0.73 \\
\hline \multicolumn{9}{|c|}{ Clinical lymph node involvement } \\
\hline No & 109 & & & & 103 & & & \\
\hline Yes & 9 & 0.52 & $(0.19 ; 1.4)$ & 0.20 & 9 & 1.5 & $(0.44 ; 5.0)$ & 0.53 \\
\hline \multicolumn{9}{|l|}{ Hydronephrosis } \\
\hline No & 97 & & & & 92 & & & \\
\hline Yes & 21 & 1.29 & $(0.73 ; 2.3)$ & 0.38 & 20 & 2.9 & $(1.2 ; 6.8)$ & 0.01 \\
\hline \multicolumn{9}{|l|}{ Tumor stage } \\
\hline T2-T3 & 108 & & & & 103 & & & \\
\hline T4 & 10 & 1.05 & $(0.45 ; 2.4)$ & 0.91 & 9 & 0.52 & $(0.07 ; 3.8)$ & 0.23 \\
\hline
\end{tabular}

NB. Due to exclusion of patients receiving less than their prescribed dose for the analysis on local recurrence, total amount of patients in this analysis is 112 , which is different from the analysis on overall survival. In addition, residual mass after resection and tumor size were not known for all patients

${ }^{\mathrm{a}} \mathrm{As}$ assessed on the CT scan made for planning purposes

Table 4 Prognostic value for overall survival and locoregional recurrence of treatment characteristics

\begin{tabular}{|c|c|c|c|c|c|c|c|c|}
\hline \multirow[t]{2}{*}{ Prognostic factors } & \multicolumn{4}{|c|}{ Overall survival } & \multicolumn{4}{|c|}{ Locoregional recurrence } \\
\hline & $n$ & $\mathrm{HR}$ & $95 \% \mathrm{Cl}$ & $p$ & $n$ & $\mathrm{HR}$ & $95 \% \mathrm{Cl}$ & $p$ \\
\hline \multicolumn{9}{|c|}{ Received radiotherapy dose } \\
\hline 55 Gy & 57 & & & & 57 & & & \\
\hline 60 Gy & 55 & 0.70 & $(0.44 ; 1.1)$ & 0.15 & 55 & 0.81 & $(0.36 ; 1.8)$ & 0.61 \\
\hline$<$ prescribed dose & 6 & 5.3 & $(2.1 ; 13.0)$ & $<0.001$ & & & & \\
\hline \multicolumn{9}{|c|}{ Radiotherapy technique } \\
\hline 3D-conformal & 67 & & & & 63 & & & \\
\hline IMRTNMAT & 51 & 1.05 & $(0.66 ; 1.7)$ & 0.83 & 49 & 0.97 & $(0.43 ; 2.2)$ & 0.95 \\
\hline \multicolumn{9}{|c|}{ Treated with image-guidance } \\
\hline No & 42 & & & & 40 & & & \\
\hline Yes & 76 & 1.43 & $(0.88 ; 2.3)$ & 0.15 & 72 & 1.0 & $(0.45 ; 2.4)$ & 0.93 \\
\hline \multicolumn{9}{|c|}{ Elective lymph node irradiation } \\
\hline No & 24 & & & & 23 & & & \\
\hline Yes & 94 & 0.60 & $(0.36 ; 1.0)$ & 0.06 & 89 & 1.1 & $(0.37 ; 3.1)$ & 0.90 \\
\hline \multicolumn{9}{|l|}{ Use of fiducial markers } \\
\hline No & 43 & & & & 40 & & & \\
\hline Yes & 75 & 0.93 & $(0.59 ; 1.46)$ & 0.75 & 72 & 0.83 & $(0.37 ; 1.9)$ & 0.66 \\
\hline
\end{tabular}



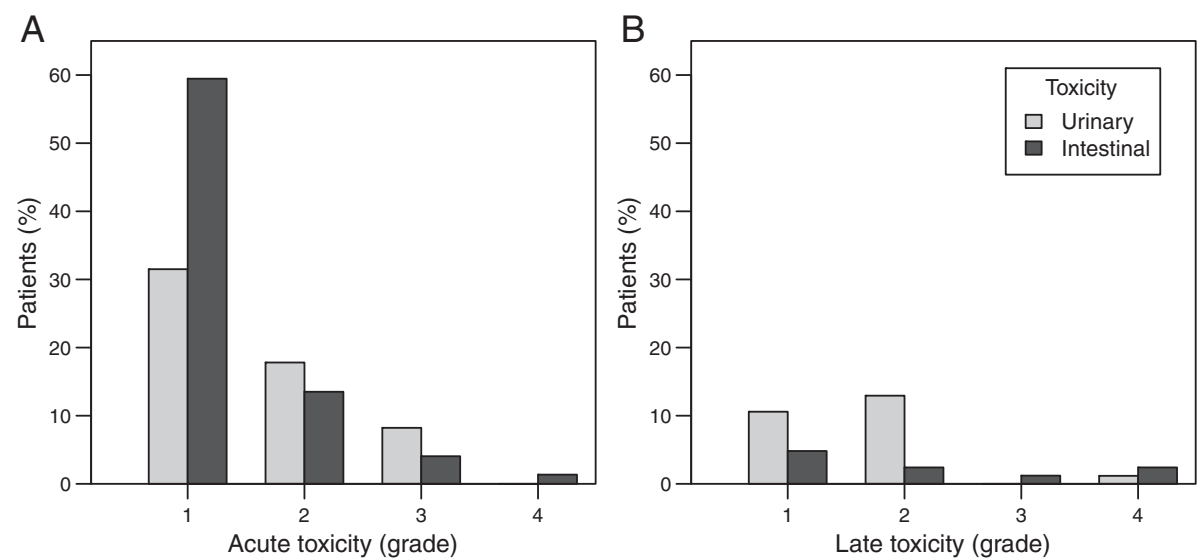

Fig. 3 Acute and late toxicity. a Acute toxicity. b Late toxicity. Light bars represent urinary toxicity, dark bars represent intestinal toxicity

dose (55 versus 60 Gy), but tumor dose also did not influence toxicity. In the absence of concurrent chemotherapy, a tumor dose of 60 Gy is therefore still advocated, except when small bowel dose constraints are exceeded, in which case a dose of 55 Gy can be applied.

Other studies report late urinary and intestinal toxicity rates grade $\geq 2$ of $10-17 \%$, and $7-10 \%$ [22, 27-29], respectively. This is comparable to our results, with rates of 14 and $5 \%$, respectively. Since the risk of global bladder injury increases for doses over 50 Gy [35], the volume receiving the boost dose of 55 Gy should be as small as possible. This is reflected in our finding that the use of fiducial markers resulted in lower rates of acute urinary toxicity; when markers were used, the margins around the tumor were smaller, and a smaller volume of the non-involved bladder received 55 Gy. In addition, studies based on high-dose whole bladder irradiation as opposed to a tumor boost, report higher rates of late urinary toxicity grade $\geq 1$ : rates of $36-62 \%$ have been reported, compared to $27 \%$ we found [22, 28]. Regarding IMRT, we found a trend towards lower rates of grade $\geq 2$ acute intestinal toxicity compared to a box technique (decrease from $33 \%$ to $12 \%, p=0.06$ ), which confirms the results of Søndergaard et al. [26]. This finding is in line with the lower bowel dose resulting from both the more conformal treatment technique, as well as the use of smaller margins $[15,16,36]$. The overall rates of toxicity in the present series were lower than the series by Søndergaard et al. which could be explained by a lower dose to the bladder and lymph nodes (40 versus 4860 Gy). Since the volume of bowel receiving at least $45 \mathrm{~Gy}$ is most predictive for intestinal toxicity [26, 37], a dose prescription $\geq 40$ Gy is expected to result in more intestinal toxicity.

The significant reduction found in both acute urinary and intestinal toxicity can be attributed to the introduction of fiducial markers, IMRT and daily image-guidance. Further increasing treatment accuracy, with the inherent reduction in margin size, could therefore further decrease toxicity. Adaptive strategies are vital in increasing treatment accuracy, since the interfractional movement of the bladder is a very large source of uncertainty. It has been shown that with an adaptive strategy, the dose to the bowel can be reduced while maintaining or improving target coverage [20, 21]. Further studies regarding outcome will determine whether this also results in a lower toxicity and a possibly higher local control.

Limitations of the present study are the retrospective nature of the data, and patient inclusion from a single institute. Our sample size was large compared to similar studies [22, 23, 25, 28], but was still relatively small concerning the univariate analyses on predictors for survival, recurrence and toxicity. For instance for survival, we only found age as predictor, whereas previously also tumor grade, tumor stage, performance status, complete resection and lymphatic invasion have been reported as predictors [10, 12, 29, 38]. In agreement with previous studies, we found hydronephrosis as a significant predictor for locoregional recurrence [9, 22, 28, 39]. It is possible that certain variables will prove to be predictors for several outcomes when a larger patient group is analyzed. Another limitation was the incomplete toxicity data, but this occurred randomly due to differences between physicians in the scoring of toxicity. A final limitation is the fact that patients treated with IMRT and VMAT were grouped together for univariate analyses. The PTV volume for VMAT is smaller since the introduction of VMAT coincided with the decision to exclude the prostate from the target volume, as well as a minor margin reduction, and this could have influenced the results. However, due to the small number of patients treated with VMAT, and the relatively small expected improvement in dose distribution [16], the effect on the analysis is assumed to be negligible. 


\section{Conclusion}

We found a 3-year overall survival of $44 \%$ for patients treated with TUR-B and curative radiotherapy for bladder cancer. Three-year locoregional control was $73 \%$, with low rates of acute and late urinary and intestinal toxicity. Toxicity rates were reduced when using IMRT and fiducial markers. Radical radiotherapy using a focal simultaneous boost is therefore a feasible and effective treatment option for elderly or unfit patients with muscle-invasive bladder carcinoma, with a high change of preservation of bladder function.

\section{Additional file}

Additional file 1: Table S1. Prognostic factors for toxicity grade $\geq 1$. Table S2. Prognostic factors for toxicity grade $\geq 2$. Table S3. Prognostic factors for toxicity grade $\geq 3$. (PDF $251 \mathrm{~kb}$ )

\section{Abbreviations}

CBCT: cone beam computed tomography; Cl: confidence interval; CTCAE: common terminology criteria for adverse events; GTV: gross tumor volume; HR: hazard ratio; IMRT: intensity-modulated radiotherapy; PTV: planning target volume; TUR-B: transurethral resection of the bladder tumor; VMAT: volumetric modulated arc therapy.

\section{Competing interests}

Lotte Lutkenhaus is assigned on an Elekta sponsored project regarding adaptive radiotherapy. Arjan Bel is project leader of several Elekta sponsored projects. Elekta had no involvement in study design, data collection and analysis. There are no other competing interests to declare.

\section{Authors' contribution}

LL performed the statistical analysis and is the main author of the manuscript. RO provided support regarding the statistical analysis. $A B$ provided support regarding study design. $\mathrm{MH}$ performed data collection and provided the database of all treated patients. $\mathrm{AB}$ and $\mathrm{MH}$ were the senior researchers providing coordination during the study. All authors have read, reviewed, and approved the manuscript.

Received: 22 December 2015 Accepted: 10 March 2016

Published online: 18 March 2016

\section{References}

1. Khosravi-Shahi P, Cabezón-Gutiérrez L. Selective organ preservation in muscle-invasive bladder cancer: Review of the literature. Surg Oncol. 2012;21:e17-22.

2. Stein JP, Lieskovsky G, Cote R, Groshen S, Feng AC, Boyd S, et al. Radical cystectomy in the treatment of invasive bladder cancer: long-term results in 1,054 patients. J Clin Oncol. 2001:19:666-75.

3. Hautmann RE, Gschwend JE, de Petriconi RC, Kron M, Volkmer BG Cystectomy for transitional cell carcinoma of the bladder: results of a surgery only series in the neobladder era. J Urol. 2006;176:486-92.

4. Shariat SF, Karakiewicz PI, Palapattu GS, Lotan Y, Rogers CG, Amiel GE, et al. Outcomes of radical cystectomy for transitional cell carcinoma of the bladder: a contemporary series from the Bladder Cancer Research Consortium. J Urol. 2006;176:2414-22.

5. Ghoneim MA, Abdel-Latif M, El-Mekresh M, Abol-Enein H, Mosbah A Ashamallah A, et al. Radical cystectomy for carcinoma of the bladder: 2,720 consecutive cases 5 years later. J Urol. 2008;180:121-7.

6. James ND, Hussain S, Hall E, Jenkins P, Tremlett J, Rawlings C, et al. Radiotherapy with or without chemotherapy in muscle-invasive bladder cancer. N Engl J Med. 2012;366:1477-88.

7. Witjes JA, Compérat E, Cowan NC, De Santis M, Gakis G, Lebret T, et al. EAU guidelines on muscle-invasive and metastatic bladder cancer: Summary of the 2013 guidelines. Eur Urol. 2014;65:778-92.
8. Lagrange J-L, Bascoul-Mollevi C, Geoffrois L, Beckendorf V, Ferrero J-M, Joly F et al. Quality of life assessment after concurrent chemoradiation for invasive bladder cancer: results of a multicenter prospective study (GETUG 97-015). Int J Radiat Oncol Biol Phys. 2011;79:172-8.

9. Efstathiou J, Spiegel DY, Shipley WU, Heney NM, Kaufman DS, Niemierko A, et al. Long-term outcomes of selective bladder preservation by combinedmodality therapy for invasive bladder cancer: the MGH experience. Eur Urol. 2012;61:705-11.

10. Munro NP, Sundaram SK, Weston PMT, Fairley L, Harrison SCW, Forman D, et al. A 10-year retrospective review of a nonrandomized cohort of 458 patients undergoing radical radiotherapy or cystectomy in Yorkshire, UK Int J Radiat Oncol Biol Phys. 2010;77:119-24

11. Arcangeli G, Strigari L, Arcangeli S. Radical cystectomy versus organ-sparing trimodality treatment in muscle-invasive bladder cancer: A systematic review of clinical trials. Crit Rev Oncol Hematol. 2015:95:1-10

12. Krause FS, Walter B, Ott OJ, Häberle L, Weiss C, Rödel C, et al. 15-year survival rates after transurethral resection and radiochemotherapy or radiation in bladder cancer treatment. Anticancer Res. 2011;31:985-90.

13. Rödel C. Combined-modality treatment and selective organ preservation in invasive bladder cancer: long-term results. J Clin Oncol. 2002;20:3061-71.

14. Galsky MD, Hahn NM, Rosenberg J, Sonpavde G, Hutson T, Oh WK, et al. A consensus definition of patients with metastatic urothelial carcinoma who are unfit for cisplatin-based chemotherapy. Lancet Oncol. 2011;12:211-4.

15. van Rooijen DC, van de Kamer JB, Hulshof MCCM, Koning CCE, Bel A. Improving bladder cancer treatment with radiotherapy using separate intensity modulated radiotherapy plans for boost and elective fields. J Med Imaging Radiat Oncol. 2010;54:256-63.

16. Foroudi F, Wilson L, Bressel M, Haworth A, Hornby C, Pham D, et al. A dosimetric comparison of $3 \mathrm{D}$ conformal vs intensity modulated vs volumetric arc radiation therapy for muscle invasive bladder cancer. Radiat Oncol. 2012:7:111.

17. Pos FJ, Hulshof M, Lebesque J, Lotz H, van Tienhoven G, Moonen L, et al. Adaptive radiotherapy for invasive bladder cancer: a feasibility study. Int J Radiat Oncol Biol Phys. 2006;64:862-8.

18. Burridge N, Amer A, Marchant T, Sykes J, Stratford J, Henry A, et al. Online adaptive radiotherapy of the bladder: small bowel irradiated-volume reduction. Int J Radiat Oncol Biol Phys. 2006:66:892-7.

19. Wright $P$, Redpath AT, Høyer M, Grau C, Muren LP. The normal tissue sparing potential of adaptive strategies in radiotherapy of bladder cancer. Acta Oncol. 2008:47:1382-9.

20. Vestergaard $A$, Muren $L P$, Lindberg $H$, Jakobsen $K L$, Petersen JBB, Elstrøm UV, et al. Normal tissue sparing in a phase II trial on daily adaptive plan selection in radiotherapy for urinary bladder cancer. Acta Oncol. 2014;53:997-1004.

21. Lutkenhaus LJ, Visser J, de Jong R, Hulshof MCCM, Bel A. Evaluation of delivered dose for a clinical daily adaptive plan selection strategy for bladder cancer radiotherapy. Radiother Oncol. 2015;116:51-6.

22. Langsenlehner T, Döller C, Quehenberger F, Stranzl-Lawatsch $H$, Langsenlehner U, Pummer K, et al. Treatment results of radiation therapy for muscle-invasive bladder cancer. Strahlentherapie und Onkol. 2010;186:203-9.

23. Piet AHM, Hulshof MCCM, Pieters BR, Pos FJ, de Reijke TM, Koning CCE Clinical results of a concomitant boost radiotherapy technique for muscleinvasive bladder cancer. Strahlentherapie und Onkol. 2008;184:313-8.

24. Pos FJ, van Tienhoven G, Hulshof MCC, Koedooder K, González GD. Concomitant boost radiotherapy for muscle invasive bladder cancer. Radiother Oncol. 2003;68:75-80.

25. Pos FJ, Van Tienhoven G, Hulshof MCCM, Koedooder K, González GD. Concomitant boost radiotherapy for muscle invasive bladder cancer. Radiother Oncol. 2003;68:75-80.

26. Søndergaard J, Holmberg M, Jakobsen AR, Agerbæk M, Muren LP, Høyer M. A comparison of morbidity following conformal versus intensity-modulated radiotherapy for urinary bladder cancer. Acta Oncol. 2014;53:1321-8.

27. Cowan RA, McBain CA, Ryder WDJ, Wylie JP, Logue JP, Turner SL, et al. Radiotherapy for muscle-invasive carcinoma of the bladder: results of a randomized trial comparing conventional whole bladder with dose-escalated partial bladder radiotherapy. Int J Radiat Oncol Biol Phys. 2004:59:197-207.

28. Yavuz AA, Yavuz MN, Ozgur GK, Colak F, Ozyavuz R, Cimsitoglu E, et al. Accelerated superfractionated radiotherapy with concomitant boost for invasive bladder cancer. Int J Radiat Oncol Biol Phys. 2003;56:734-45.

29. Chahal R, Sundaram SK, Iddenden R, Forman DF, Weston PMT, Harrison SCW. A study of the morbidity, mortality and long-term survival following radical cystectomy and radical radiotherapy in the treatment of invasive bladder cancer in Yorkshire. Eur Urol. 2003;43:246-57. 
30. Kang JJ, Steinberg ML, Kupelian P, Alexander S, King CR. Whole Versus Partial Bladder Radiation. Am J Clin Oncol. 2015;00:1.

31. Whalley D, Caine H, Mccloud P, Guo L, Kneebone A, Eade T. Promising results with image guided intensity modulated radiotherapy for muscle invasive bladder cancer. Radiat Oncol. 2015;1-9.

32. Hsieh C-H, Chung S-D, Chan P-H, Lai S-K, Chang H-C, Hsiao C-H, et al. Intensity modulated radiotherapy for elderly bladder cancer patients. Radiat Oncol. 2011;6:75.

33. Hulshof MCCM, van Andel G, Bel A, Gangel P, van de Kamer JB. Intravesical markers for delineation of target volume during external focal irradiation of bladder carcinomas. Radiother Oncol. 2007:84:49-51.

34. Chai $X$, van Herk $M$, van de Kamer JB, Remeijer P, Bex A, Betgen A, et al. Behavior of lipiodol markers during image guided radiotherapy of bladder cancer. Int J Radiat Oncol Biol Phys. 2010;77:309-14.

35. Marks LB, Carroll PR, Dugan TC, Anscher MS. The response of the urinary bladder, urethra, and ureter to radiation and chemotherapy. Int J Radiat Oncol Biol Phys. 1995;31:1257-80.

36. Søndergaard J, Høyer M, Petersen JB, Wright P, Grau C, Muren LP. The normal tissue sparing obtained with simultaneous treatment of pelvic lymph nodes and bladder using intensity-modulated radiotherapy. Acta Oncol. 2009;48:238-44.

37. Kavanagh BD, Pan CC, Dawson LA, Das SK, Li XA, Ten Haken RK, et al. Radiation dose-volume effects in the stomach and small bowel. Int J Radiat Oncol Biol Phys. 2010;76:101-7.

38. Kotwal S, Choudhury A, Johnston C, Paul AB, Whelan P, Kiltie AE. Similar treatment outcomes for radical cystectomy and radical radiotherapy in invasive bladder cancer treated at a United Kingdom Specialist Treatment Center. Int J Radiat Oncol. 2008;70:456-63.

39. Milosevic M, Gospodarowicz M, Zietman A, Abbas F, Haustermans K Moonen L, et al. Radiotherapy for Bladder Cancer. Urology. 2007;69:80-92

\section{Submit your next manuscript to BioMed Central and we will help you at every step:}

- We accept pre-submission inquiries

- Our selector tool helps you to find the most relevant journal

- We provide round the clock customer support

- Convenient online submission

- Thorough peer review

- Inclusion in PubMed and all major indexing services

- Maximum visibility for your research

Submit your manuscript at www.biomedcentral.com/submit

C Biomed Central 